\title{
Cannabis publication analysis using density-equalising mapping and research output benchmarking
}

B H Vogelzang, MB ChB, MSC (Med), DMH (SA)

C Scutaru, MA

S Mache, PhD

K Vitzthum, MA

B Kusma, MA

K Mutawakel, MD

D A Groneberg, MD, PhD

D Quarcoo, MD

Institute of Occupational Medicine, Charité Universitätsmedizin Berlin, Free University and Humboldt University, Berlin, Germany

Background. Cannabis has been a topic of political and medical controversy in many countries over the past century. Although many publications on this topic are available, there is currently no comprehensive evaluation of global research activities in the field.

Objective. This study was conducted in order to provide a quantitative and qualitative analysis of the worldwide research output on cannabis.

Methods. In a quantitative approach, items concerning cannabis published between 1900 and 2008 were retrieved from the ISI Web of Science databases developed by the Thompson Institute of Scientific Information and analysed using scientometric methods. In a second step, research fields of growing interest were identified.

Results. We found that publications on this topic increased during the late 1960s, as well as during the period 1990. 2008. We noted that South Africa was one of the countries with a high research output, having published numerous articles on cannabis. A comparison of cannabis with other drugs (e.g. alcohol, tobacco, cocaine and heroin) showed that in relation to the proportion of respective drug users, cocaine and heroin are overly represented in terms of research output. When analysing the main subjects of the publications, psychiatry was prominent, especially with regard to research on psychosis.
Conclusion. There is increasing interest in research on cannabis. The research only partially reflects the drug's importance with regard to number of users.

Cannabis, also known as grass, pot or marijuana, has spurred abundant controversy over the past century. In the UK this conflict reached a turning point in January 2004, when the British government downgraded cannabis from a class $B$ drug to a class $C$ drug, causing widespread concern among health care workers and the general public. In the light of the research on cannabis, the British government responded with a new initiative that reclassified it as a class B drug in January 2009. 1,2 However, not all EC countries share this view on cannabis legislation. In the Netherlands a softer approach is preferred, and possession of small amounts of cannabis is legal according specific regulations in particular locations called 'coffee shops'. The argument is that 'Coffee shops are tolerated in the attempt to keep young people, who experiment with cannabis, away from other much more dangerous drugs'. ${ }^{3}$

In the USA, a law passed in 1944 legally banned research on cannabis for medical purposes. This law was based on a committee report by the then New York mayor, Fiorello LaGuardia, ${ }^{4}$ in which he stated that cannabis consumption leads to tolerance, resulting in a need for a higher dose to achieve the same effect. The law was introduced by Harry J Anslinger from the Federal Bureau of Narcotics and was amended in 1962 after his retirement. ${ }^{5}$ The discussion of cannabis legalisation continues today. A recent event was the passing of the first marijuana decriminalisation law on 4 November 2008 in Massachusetts, USA, which reduced the legal consequences of possession of small amounts of cannabis. ${ }^{6}$

Cannabis is significant not only in terms of the conflict that rages over its legal status, but also because of its widespread use and the resulting legal and medical costs. Cannabis is estimated to be the world's third most popular recreational drug, following alcohol and tobacco, with an estimated 160 million people (4\% of the world's population) using cannabis annually. This widespread use is particularly worrying in the light of data that have established cannabis use as a non-genetic risk factor 
associated with schizophrenia. ${ }^{10}$ Its ability to induce psychosis was first documented by the French psychiatrist Moreau de Tours in 1845." "Furthermore, patients with subclinical psychoses have poorer outcomes and require more clinical care when they are exposed to cannabis. ${ }^{12}$

In terms of years of potential life lost (YPLL), cannabis rated higher than cocaine in Australia for the period $1997-2004,{ }^{14}$ the YPLL for cannabis being 9.46 years and that for cocaine 6.91 years. Other recreational drugs, such as heroin (61.22 years) and alcohol (40.02 years), rated higher. In a study in Ohio, USA, conducted from 1998 to 2002, it was found that 59 cannabis users died during this time period, compared with 35 cocainerelated deaths. ${ }^{15}$ Both these studies indicate that in terms of potential loss of life the cost of cannabis to societies is higher than that of cocaine.

In contrast to these harmful aspects of cannabis is its beneficial use as a medicinal drug. Cannabis exhibits analgesic properties that have been used in people with chronic pain, as well as to provide relief from spasticity in multiple sclerosis. ${ }^{8}$ Cannabis (under the trade name Marinol) is currently available for medical use in the USA to relieve nausea and vomiting associated with chemotherapy in cancer patients, as well as to prevent loss of appetite associated with AIDS. ${ }^{\text {? }}$

The various aspects of cannabis have been described in numerous publications over the years. These aspects have never been scientometrically examined. The objective of this study was therefore to analyse trends in cannabis research from 1900 to 2008 in terms of publication date, countries of origin, main topics, and main research areas of the 10 most published authors. We were also interested in comparing cannabis with other harmful substances (alcohol, tobacco, cocaine and heroin) with regard to the number of publications relative to the number of respective users.

\section{Methods}

\section{Data source}

The data for this project were retrieved from the Web of Science (ISI-Web) database of the Thomson Institute for Scientific Information. 16,17

\section{Search strategies}

The phrase 'cannabis*' was used in order to find all scientific publications that address cannabis. The asterisk was added to root words to include stem words with all possible endings. As a comparison, a similar search was conducted using the words 'alcohol*', 'tobacco*', 'cocaine*' and 'heroin*'.

\section{Time span}

The time span analysed was from 1900 to 2008. The year 2009 was not included because not all publications for that year were available at the time of assessment. For the searches on alcohol, tobacco, cocaine and heroin, the time span was limited to 1990 - 2008. A clear increase in papers on cannabis during this time could therefore be illustrated accurately, and it was possible to compare the literature on cannabis with increases in publications on the other substances listed above.

\section{Citation measures}

The 'citation report' function was used to analyse the published items. It uses the sum number of the times a publication has been cited and divides it by the number of results found. The number of times a specific journal or author was cited could thus be evaluated as an indicator of research quality. The following citation databases were used: (i) Science Citation Index Expanded (SCI-EXPANDED) - 1900 to present; (ii) Social Sciences Citation index (SSCI) - 1956 to present; and (iii) Arts \& Humanities Citation Index (A\&HCl) - 1975 to present.

\section{Density-equalising mapping}

In this method, specific calculations based on Gastner and Newman's algorithm ${ }^{18}$ were used in order to produce a map of the world, in which the different countries were resized according to specific variables - in this case, according to the total cannabis publications from each country.

\section{Analysis of publication content}

Based on the ISI-Web database, the top 10 authors in cannabis research from 1900 to 2008 were identified and their publications analysed with regard to the topics of their work. The main themes of the authors were tabulated.

\section{Results}

\section{Total number of publications}

A total of 6376 publications on cannabis were published between 1900 and 2008. Of these, 1.9\% (122) were published in $1900-1966$ and $24.6 \%(1$ 568) in 1967 - 1994. The rest $14686,73,5 \%$ ) were published in 1995 - 2008. These figures indicate clear increases in the number of publications during the late 1960s, as well as since the 1990s (Fig. 1). 
As cannabis is the world's third most popular recreational drug after alcohol and tobacco, ${ }^{6}$ we compared the rate of increase in papers on cannabis over the past decade with the rates of increase in papers on other drugs: alcohol, tobacco, cocaine and heroin. The number of publications on alcohol increased from 8119 in 1999 to 12048 in 2008, those on tobacco from 3148 to 4 368, those on cannabis from 190 to 634 , those on cocaine from 1617 to 1864 , and those on heroin from 455 to 660 (Fig. 2). These figures would indicate the following publication ratios: cannabis to alcohol 1:8.9, cannabis

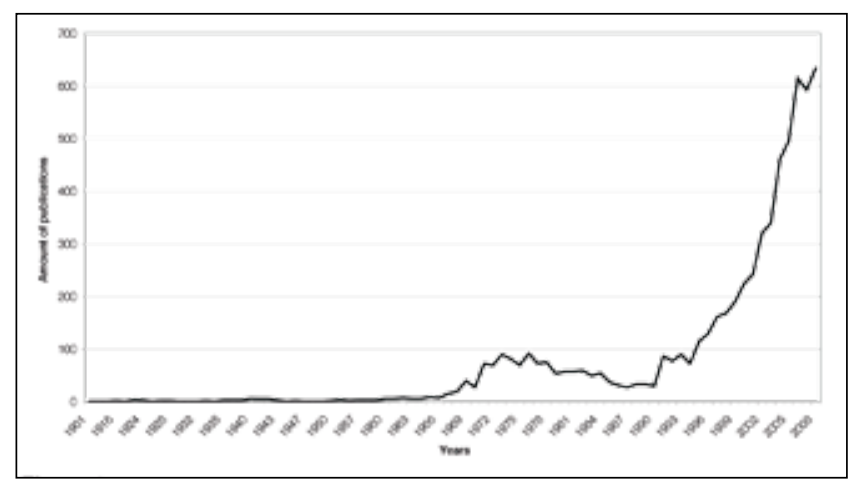

Fig. 1. Publications relating to cannabis in the ISI-Web database, 1900 - 2008.

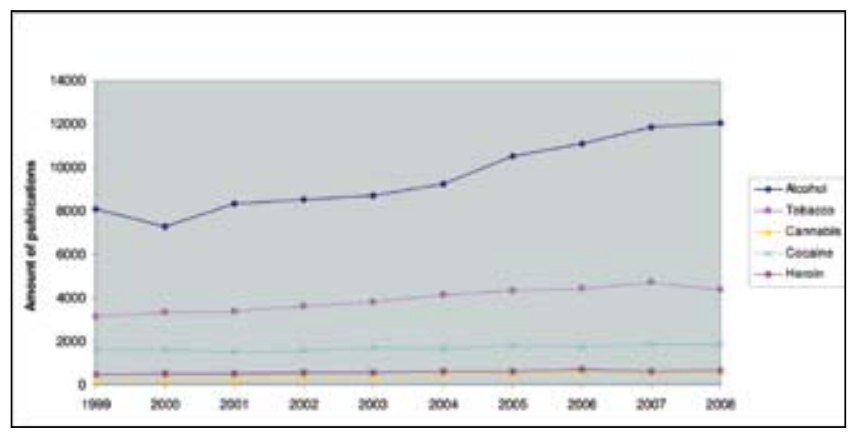

Fig. 2. Comparison of numbers of publications on alcohol, tobacco, cannabis, cocaine and heroin, 1999 - 2008. to tobacco 1:2.7, cannabis to cocaine 1:0.6, and cannabis to heroin $1: 0.5$

\section{Origin}

One-quarter of the 6376 items published between 1900 and 2008 originated from researchers in the USA, 14\% from the UK, $8 \%$ from Australia and $6 \%$ from Germany. Table I presents the 20 most prolific countries. Using density-equalising mapping, a rescaled map of the world was created to depict the number of publications per country (Fig. 3).

As a measure of the quality of the publications from the different countries, we used the average citation rate and compared the countries that have published at least 30 papers. We found that Italy (21.84), Sweden (19.13) and Israel (18.59) had the highest average citation rates. The three countries with the largest amount of publications, the USA, the UK and Australia, had average citation rates of 17.89, 14.04 and 11.54 , respectively. Using density-equalising mapping, a rescaled map of the world was created to depict the average citation rates of the countries with at least 30 publications (Fig. 4).

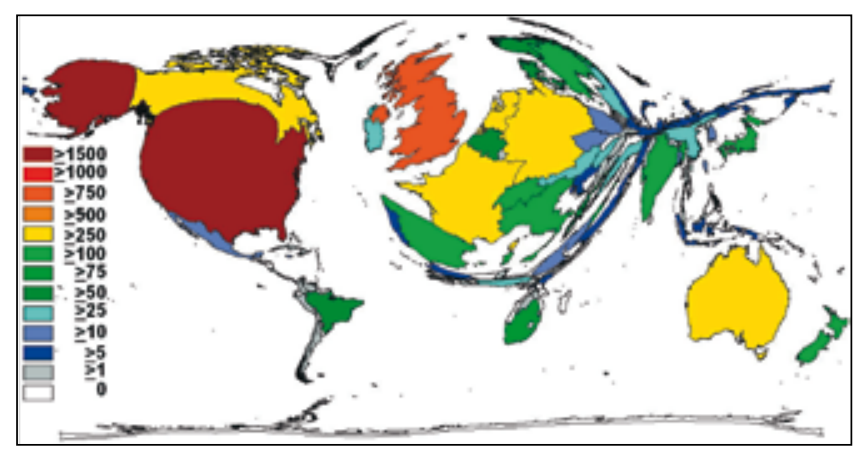

Fig. 3. Density-equalising map illustrating the number of publications in each country. The area of each country was scaled in proportion to its total number of publications on cannabis.

Table I. The 20 most prolific countries with regard to publications on cannabis, 1900 - 2008

\begin{tabular}{|c|c|c|c|c|c|}
\hline Rating & Country & Publications (N) & Rating & Country & Publications (N) \\
\hline 1 & USA & 1646 & 11 & New Zealand & 150 \\
\hline 2 & UK & 913 & 12 & India & 134 \\
\hline 3 & Australia & 500 & 13 & Sweden & 111 \\
\hline 4 & Germany & 360 & 14 & Japan & 102 \\
\hline 5 & France & 345 & 15 & Israel & 83 \\
\hline 6 & Canada & 341 & 16 & South Africa & 81 \\
\hline 7 & Netherlands & 292 & 17 & Brazil & 68 \\
\hline 8 & Spain & 226 & 18 & Belgium & 57 \\
\hline 9 & Switzerland & 208 & 19 & Norway & 56 \\
\hline 10 & Italy & 204 & 20 & Denmark & 53 \\
\hline
\end{tabular}


To establish the extent of co-operation between countries, a radar chart graph was used to depict the partnered countries and quantity of collectively published items (Fig. 5). Twenty-five countries co-operated in publishing at least five papers with other countries. The countries that co-operated most frequently with other countries were the USA, the UK, Germany, Canada and the Netherlands. The two countries with the highest share of collaborative publications were the Netherlands and Germany. Thirty-one per cent of Dutch and 25\% of German cannabis publications were the result of international collaboration. The fraction of co-operative articles for the two most prolific countries (USA and UK) was $17 \%$.

\section{Subject area analysis}

To investigate the various subject areas in which papers on cannabis were published, the top five subject areas in the field

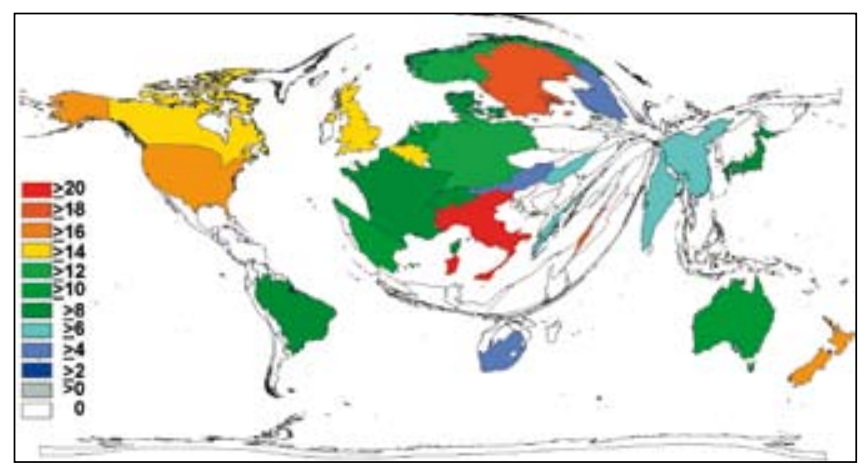

Fig. 4. Density-equalising map illustrating the average citation rate of the countries that published at least 30 papers on cannabis from 1900 to 2008. The area of each country was scaled in proportion to its average citation rate on cannabis publications.

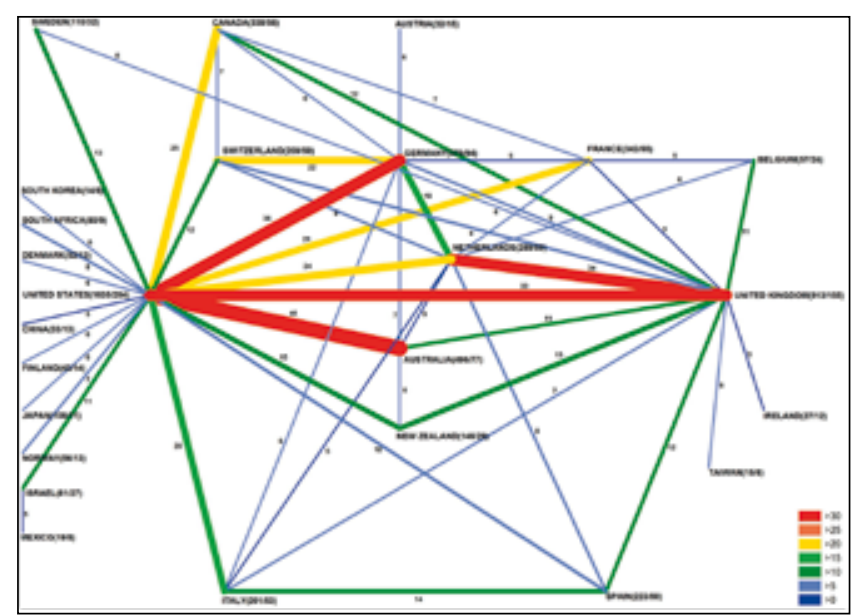

Fig. 5. Comparison of countries with at least five collaborative publications. Format: country (amount of publications/ amount of publications in co-operation with other countries). of cannabis from 1999 to 2008 were compared in terms of their respective percentages over the past four decades (Fig. 6). Of cannabis publications, those in psychiatry, the neurosciences and clinical neurology have been increasing continuously over the past five decades - more steeply during the past three decades. During the period 1959 - 1968, these three subject areas accounted only for $9.5 \%$ of cannabis publications. This percentage increased to $21.9 \%$ in the period 1979 - 1988 and then more than doubled to $55.7 \%$ for the decade 1999 - 2008.

\section{Analysis of content of publications}

To get an idea of the content of research in the field based on the ISI-Web database, the main themes of the 10 most publishing authors in cannabis research from 1900 to 2008 were identified and their publications analysed. Five of the most prolific authors published papers on the biochemical and pharmacological aspects of the various substances found in the cannabis plant. The same number of authors published on subjects related to clinical psychiatry, the effects of cannabis use, cannabis dependence, psychosis (4 of 10 authors), and depression. The investigation of various substances found in the cannabis plant and the pharmacological aspects of their effects was another important subject (Table II).

\section{Discussion}

This paper describes the findings of a scientometric analysis of all available publications on the subject of cannabis published between 1900 and 2008. We found increases in publication numbers during the 1960s and a major rise since the 1990s. We also analysed the number of publications on cannabis compared with alcohol, tobacco, cocaine and heroin. The latter three substances showed some discrepancies in publication numbers

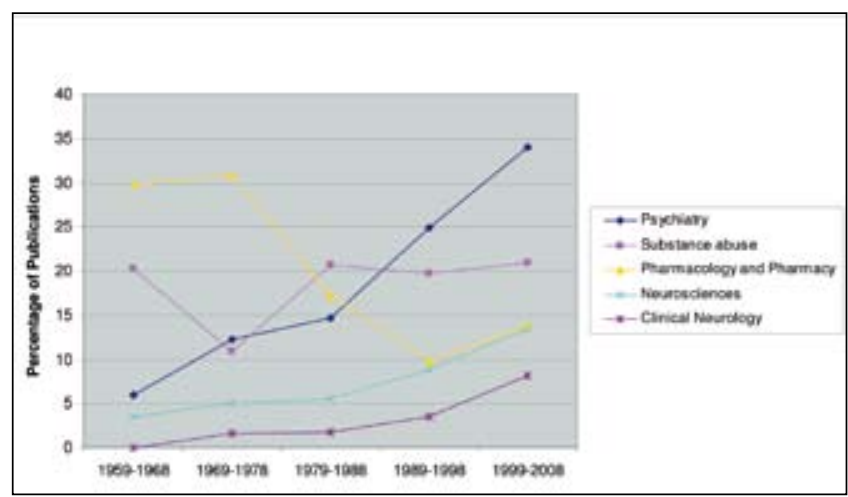

Fig. 6. Comparison of the top five subject areas in which papers on cannabis were published from 1999 to 2008 with those of the previous five decades. 
relative to respective drug use. In determining which countries published papers on this topic, we found that publications on cannabis originated from 109 countries and that widespread co-operation of countries on this subject was apparent. Finally we analysed the content of cannabis publications by examining the main subjects of the published papers, as well as the main themes of the top 10 authors.

The first work on cannabis according to the ISI database was published in 1901. The paper examined the experimental transformation of etamine to cannabis and was published in French by M Molliard in the journal Comptes Rendus des Séances de la Société de Biologie et des Filiales. ${ }^{19}$ A preceding work that does not appear in the ISI-Web database is the description of a self-experiment on the mental effects of cannabis published in 1893 in the journal Science. ${ }^{20}$ Since these early works, the annual rate of publications has increased continuously. Our analysis shows that there were two periods of accelerated research output in terms of the numbers of papers published since 1901 - the late 1960s and the mid-1990s. Seen in a historical context, the first increase might be associated with the readmission of medical cannabis research in the USA, which was legally banned between 1944 and 1962.5 An event that might also have influenced research output was a report published by Wootton in the UK in 1968. ${ }^{21}$ It doubted the relevance of retribution for illicit drug use and called for more research to determine the dangers of cannabis. Furthermore, in the 'hippie' subculture of the time there was a fairly liberal attitude towards illegal substances, and cannabis use was widespread. ${ }^{22}$

The increase in publications since 1990 has also been shown in other research fields such as psoriasis ${ }^{23}$ and rheumatoid arthritis. ${ }^{24}$ This increase has been attributed to the boost in scientific exchange resulting from better means of electronic communication since the 1990s. ${ }^{26}$ A change in the exploration algorithm that the ISI database implemented in the 1990s might also have contributed to the steep rise. ${ }^{25}$ In 1963, de Sola Price published a theory claiming that scientific output will double every $10-15$ years. ${ }^{27}$ We found that publications on cannabis increased by 15 times from 1990 to 2006, a much bigger increase than suggested by

\section{Table II. The 10 authors who published most papers on cannabis, $1900-2008$, and a summary of the main topics of each author}

\begin{tabular}{|c|c|c|}
\hline Author & Publications (N) & Summary of the publication themes \\
\hline Hall W & 62 & $\begin{array}{l}\text { Cannabis use and psychosis, depression and other substance use, prevalence } \\
\text { of cannabis use, cannabis use in young people, cannabis policy in Australia, } \\
\text { cannabis and medical conditions }\end{array}$ \\
\hline Turner CE & 57 & $\begin{array}{l}\text { Constituents of Cannabis sativa L } 1-25 \text {, pharmacological action of cannabis } \\
\text { constituents, isolation of cannabinoids, isolation of cannabispiran, isolation of } \\
\text { cannabisativine }\end{array}$ \\
\hline Elsohley Y & 49 & $\begin{array}{l}\text { Constituents of C. sativa, pharmacological action of cannabis constituents, } \\
\text { analysis of cannabis oil and seeds, non-cannabinoid constituents of } C \text {. sativa }\end{array}$ \\
\hline Van Os J & 44 & $\begin{array}{l}\text { Cannabis use and psychosis, cannabis use and bipolar disorder, cannabis use } \\
\text { and schizophrenia, cannabis use and young people }\end{array}$ \\
\hline Mechoulam R & 43 & $\begin{array}{l}\text { Chemistry and biochemistry of cannabis, medical use of cannabis, } \\
\text { pharmacological aspects of cannabidiol, cannabidiol research in rats, } \\
\text { cardioprotective effect of cannabidiol }\end{array}$ \\
\hline Degenhardt L & 42 & $\begin{array}{l}\text { Epidemiology of cannabis, cannabis use, drug-related hospital separations in } \\
\text { Australia, cannabis and psychosis, cannabis and young people }\end{array}$ \\
\hline Fergusson DM & 41 & $\begin{array}{l}\text { Cannabis and driving, cannabis use and later-life outcomes, cannabis and } \\
\text { psychosis and other drug use, cannabis and crime, cannabis use in New } \\
\text { Zealand, cannabis and young people }\end{array}$ \\
\hline Shoyama Y & 39 & $\begin{array}{l}\text { Biosynthetic studies on C. sativa, analysis of cannabis enzymes, } \\
\text { biotransformation of cannabidiol and cannabidiolic acid, cannabichromenic } \\
\text { acid biosynthesis }\end{array}$ \\
\hline Lynskey MT & 34 & $\begin{array}{l}\text { Autosomal linkage scan for cannabis use disorders, cannabis use and nicotine } \\
\text { dependence, cannabis use and alcohol, cannabis use in woman, genetic } \\
\text { epidemiology of cannabis use }\end{array}$ \\
\hline Mahlberg PG & 33 & $\begin{array}{l}\text { Morphology of glandular hairs of cannabis, cannabinoid content of different } \\
\text { plant organs, analysis of cannabinoid composition }\end{array}$ \\
\hline
\end{tabular}


the de Sola Price theory. Furthermore this rate is higher than those in many other research fields for the same period of time (burns 3.5, pulmonary hypertension 5.8 times, leishmaniasis 7.5 times, sarcoidosis 3.2 times), suggesting an above-average interest in cannabis research.

Next we explored whether the research on cannabis reflects the importance of the drug with regard to number of users. Taking into account that there are differences in the way data are collected and processed, we used the available statistical data from the EU and the USA as a measure of current use of alcohol, tobacco, cannabis, cocaine and heroin. ${ }^{28-32}$ Using these estimates we found that the research output for alcohol compared with cannabis reflected numbers of users of these drugs. Research on tobacco under-represented use, while for cocaine and heroin research over-represented use. In a recent study in the Lancet, dangerous drugs were compared by looking at the harm they do to the individual, the harm they do to society, and whether or not they induce dependence. ${ }^{33}$ This study rated heroin as the most dangerous drug; cocaine was second, alcohol fifth, tobacco ninth and cannabis eleventh.

When analysing publications according to country of origin, we unexpectedly found South Africa's research output comparable to that of the most prolific countries. The data indicate that South Africa publishes more on this subject than on other subjects such as asthma, ${ }^{34}$ psoriasis $^{23}$ or rheumatoid arthritis. ${ }^{24}$ This difference could be attributed to the major impact of cannabis on social and economic issues in South Africa. According to the 'strategic program framework on crime and drugs for southern Africa 2003' from the United Nations office for drugs and crime, ${ }^{35}$ Interpol estimates that South Africa is among the top four sources of herbal cannabis in the world. This study attributes this to South Africa's economic dominance in southern Africa, its range of sophisticated assets (compared with the rest of the region), the explosive increase in organised crime since 1994, widespread corruption in both the official and the private sectors, and the availability of crime and criminal justice data. The report also states that the South African government appears serious in its efforts to counteract domestic and transnational crime, which would have positive effects on that country as well as on the whole of southern Africa. Of special interest was the situation in Lesotho, where cannabis is regarded as the main cash crop. Future analysis will shed more light on developments over time.

We also compared the countries that published most papers with the average citation rates, as a measure of the quality of the publications. We found that Italy, Sweden and Israel had higher average citation rates than the countries that published most papers, i.e. the USA, the UK and Australia. This could indicate that the countries with high average citation rates published more general papers, which had a higher impact and were therefore read by more people. Lower average citation rates could be due to more subject-specific publications, which were read by less people and therefore cited less.

With regard to co-operation between countries, we found that countries with high output in other research fields, such as the USA, the UK, Germany, Canada and the Netherlands, often co-operated with each other and with other countries. ${ }^{23}$

In analysing the contents of the publications, we took two different approaches. First an overall impression was obtained by looking at the subject areas of the publications. We found that the areas of psychiatry, neuroscience and clinical neurology increased in importance over time, accounting for more than $50 \%$ of the publications compared with those in other subject areas over the past decade. This increase could be attributed to the negative side-effects of cannabis, especially psychoses and mental health problems in young people. ${ }^{36}$ The increases in publications in clinical neurology and the neurosciences might be due to the therapeutic uses of cannabis in neurological conditions such as chronic pain, multiple sclerosis, nausea caused by chemotherapy, and loss of appetite in AIDS patients. ${ }^{8,9}$

In a second approach, we analysed the main topics of the publications of the 10 authors with most publications. We found that the most prolific authors were interested in the pharmacological contents of the cannabis plant and the effects of cannabis use, especially dependency, psychosis and depression. 4,8,9,12,13 These themes also reflect the two sides of cannabis use as they are generally perceived: concern about the plant's effects, especially with regard to the young age of users ${ }^{36}$ and major psychiatric conditions $^{10}$ that are harmful to both the individual and society, and the hope placed on the plant's potential use in alleviating certain medical conditions.

The authors thank the staff at the Institute of Occupational Medicine at the Charité Medical University, the Humboldt University and the Free University in Berlin.

Conflicts of interest. The authors declare that they have no conflicts of interest.

Authors' contributions. DQ and BHV designed the study. $\mathrm{CS}$ and $\mathrm{BHV}$ constructed the different graphs and did the data analysis. BHV did the research and wrote the paper. DAG, SM 
and KV assisted in the layout and evaluation of the paper. DQ co-ordinated the project.

\section{References}

1. www.homeoffice.gov.uk/drugs/drugs-law/cannabis-reclassification/accessed 5 March 2009)

2. http://www.homeoffice.gov.uk/drugs/drugs-law/Class-a-b-c/ laccessed 15 August 2009)

3. http://eldd.emcdda.europa.eu/html.cfm/index5174EN.html\# [select country profile: 'Netherlands'] (accessed 27 August 2009)

4. La Guardia FH. The la Guardia Committee Report, The Marihuana Problem in the City of New York. Mayor's Committee on Marihuana. New York: New York Academy of Medicine, 1944.

5. Mcwilliams JC. The Protectors: Harry J Anslinger and the Federal Bureau of Narcotics 1930 - 1962. Newark, NJ: University of Delaware Press, 1990

6. http://www.boston.com/news/local/breaking_news/2008/11/question_2_setu. html laccessed 6 October 2009)

7. Murray RM, Morrison PD, Henquet C, Di Forti M. Cannabis, the mind and society: the hash realities. Nature Reviews Neuroscience 2007;8:885-895.

8. Pacher P, Batkati S, Kunos $G$. The endocannabinoid system as an emerging target of pharmacotherapy. Pharmcol Rev 2006;58:389-462

9. http://www.usdoi.gov/dea/ongoing/marinol.html (accessed 6 October 2009).

10. Henquet $C$, Murray R, Linszen D, van Os J. The environment and schizophrenia: the role of cannabis use. Schizophr Bull 2005;31:608-612.

11. Moreau لl. Hashish and Mental Illness. New York: Raven, 1973.

12. Van Os J, Linscott RJ, Myin-Germeys I, Delespaul P, Krabbendam L. A systematic review and meta-analysis of the psychosis continuum: evidence for a psychosis proneness-persistence-impairment model of psychotic disorder. Psychol Med 2009;39:179-195.

13. Boreham R, Cronberg A, Dollin L, Pudney S. The Arrestee Survey 2003-06. Home Office Statistical Bulletin 12/07. London: Home Office, 2007

14. http://www.scribd.com/doc/21202186/Reece-submission-to-Limits-of-harmMinimisation-Inquiry (accessed 27 October 2009)

15. Miller BJ, Bayard Paschall C, Svendsen DP. Mortality and medical morbidity among patients with serious mental illnesses. Psychiatric Services 2006;57:1482-1487.

16. Sevnic A. Multilingual approach to 'Web of Science'. J Natl Med Assoc 2005:97:116-117
17. Sevnic A. Web of science: A unique method of cited reference searching. J Natl Med Assoc 2004;96:980-983.

18. Gastner MT, Newman ME. From the cover: Diffusion-based method for producing density-equalizing maps. Proc Natl Acad Sci USA 2004; 101:7499-7504.

19. Molliard M. The experimental transformation of etamine in cannabis. Comptes Rendus des Séances de la Société de Biologie et des Filiales 1901;53:851-853.

20. Scripture EW. Consciousness under the influence of Cannabis indica. Science 1893;XXII(560):233-234

21. http://www.ukcia.org/research/wootton/index.htm\#index laccessed 10 September 2009)

22. Radenkowa-Saeva J. Recreational drugs and their influence on music, literature and art. Biotechnol Biotec EQ 2008:22(2):656-659.

23. Schöffel N, Mache S, Al-Mutawakel K, Quarcoo D, Scutaru DA, Vitzthum K. A new view on psoriasis research efforts. J Eur Acad Dermatol Venereol 2010:24(1):85-88.

24. Schöffel N, Mache S, Quarcoo D, et al. Rheumatoid arthritis: scientific development from a critical point of view. Rheumatol Int 2010; 30(4): 505-513.

25. http://images.isiknowledge.com/WOK46/help/WOS/h_database.html\#ssci laccessed 6 October 20091.

26. Glowniak J. History, structure, and function of the Internet. Semin Nucl Med 1998;28(2): 135-144.

27. De Sola Prince D. Little Science, Big Science. Frankfurt: Suhrkamp, 1974

28. http://whqlibdoc.who.int/hq/2000/WHO_MSD_MSB_00.4.pdf laccessed 17 October 2009)

29. http://www. oas. samhsa.gov/NSDUH/2k8NSDUH/2k8Results. htm\#Fig2-1 (accessed 17 October 2009).

30. http://www.emcdda.europa.eu/drug-situation (accessed 17 October 2009).

31. http://ec.europa.eu/health-eu/news_alcoholineurope_en.htm laccessed 17 October 2009)

32. Strong $K$, Guthold $R$, Yang J, Lee $D$, Petit $P$, Fritzpatrick $C$. Tobacco use in the European union. Eur J Cancer Prev 2008; 17(2): 162-168.

33. Nutt D, King LA, Saulsbury W, Blakemore C. Development of a rational scale to assess the harm of drugs of potential misuse. Lancet 2007:369: 1047-1053.

34. Börger J-A, Neye N, Scutaru C, et al. Models of asthma: density equalising mapping and output benchmarking. J Occup Med Toxicol 2008;3(Suppl 1): S7.

35. http://www.unodc.org/pdf/southafrica/spf_2003.pdf laccessed 17 October 2009).

36. http://news.bbc.co.uk/2/hi/programmes/panorama/4104702.stm laccessed 17 October 2009) 